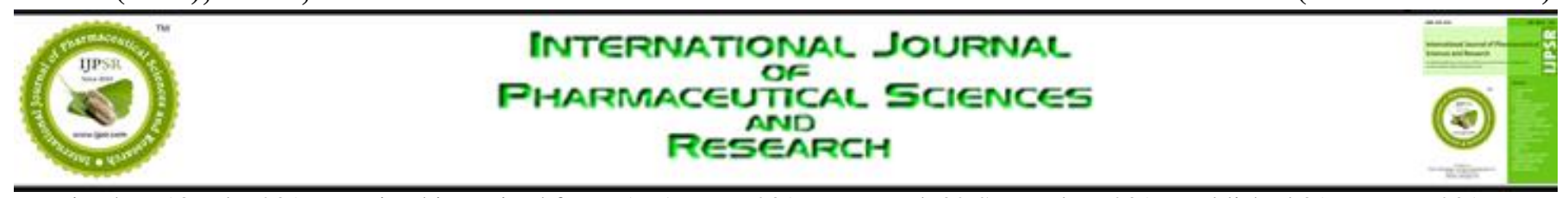

Received on 13 July, 2016; received in revised form, 19 August, 2016; accepted, 02 September, 2016; published 01 January, 2017

\title{
SCREENING OF MARINE SOILS FROM BAY OF BENGAL NEAR CHIRALA COAST OF ANDHRA PRADESH FOR ISOLATION OF LIPOLYTIC ACTINOBACTERIA AND CHARACTERIZATION OF THE MOST POTENT ISOLATES
}

\author{
A. Rajanikanth ${ }^{1}$ and T. Damodharam ${ }^{* 2}$
}

Department of Biotechnology ${ }^{1}$, Department of Environmental sciences ${ }^{2}$, Sri Venkateswara University, Tirupati, Andhra Pradesh, India.

\section{Keywords:}

Actinobacteria, Lipase, Streptomyces fungicidicus, Bay of Bengal, Gene Bee, NEB Cutter.

\section{Correspondence to Author: \\ Dr. T. Damodharam}

Professor and Head Dept of Environmental Sciences S.V.U College of Sciences, Sri Venkateswara University, Tirupati517502, AP, India.

Email: thotidamodharam@yahoo.co.in

\begin{abstract}
Three marine soil samples collected at various seashores of the Bay of Bengal near Chirala Coast of Andhra Pradesh were screened for the isolation of lipolytic Actinobacteria by tributyrin agar clearing method. The isolates were cultured under submerged fermentation conditions and assayed for their extra cellular lipase producing capabilities using olive oil as substrate. Enzyme profiling of the selected strain was done by incorporating the respective substrates in the media. The different parameters namely, morphological, biochemical, physiological and molecular were used for the characterization and identification of actinomycetes isolates. The secondary structure and restriction site of selected actinomycetes were predicted using bioinformatics tools available online. Results indicated that all the isolates showed lipolytic activity after primary screening. These isolates were subjected to secondary screening and lipase activity is estimated quantitatively. Morphological, cultural, physiological and biochemical characteristics as well as enzymatic activities suggested that all the isolates belonging to the genus Streptomycetes. The marine isolate RPBS-A4 was the most active one and thus was selected further identification. The 16S rDNA amplification for phylogenetic study revealed that the isolate was highly related to Streptomyces fungicidicus ( 97\%), so it is designated as Streptomyces fungicidicus RPBS-A4. The RNA secondary structure showed that the free energy of the structure is $-124.0 \mathrm{kcal} / \mathrm{mol}$. Threshold energy is -4.0 with cluster factor 2 , conserved factor 2 and compensated factor 4 and conservativity is 0.8 . It showed restriction sites for 50 enzymes, GC and AT content of 61 and $39 \%$, respectively.
\end{abstract}

INTRODUCTION: Lipases are obtained from microorganisms which produce a wide variety of extracellular lipases ${ }^{1}$. Commercial lipases are obtained from microorganisms as they are more stable compared to plant or animal lipases and they can be obtained cheaply. In the field of biotechnology, much attention has been paid to the use of lipases of microbial origin.

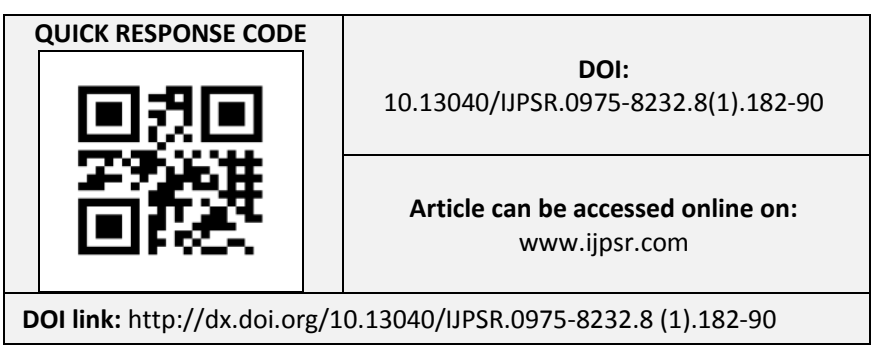

They constitute the most important group of biocatalysts having tremendous biotechnological potential because, firstly, they can be produced in large quantities from microbial sources, secondly, they display exquisite chemo selectivity, regioselectivity and stereo selectivity and thirdly, the crystal structures of many lipases have been solved, facilitating considerably the design of rational engineering strategies. These properties make lipases the most widely used group of biocatalysts in organic chemistry ${ }^{2}$. Important applications of lipases in Biotechnology includes their supplementation to detergents, in the manufacture of food ingredients, pitch control in the pulp and paper industry, and biocatalysis of stereo selective transformations. 
Actinomycetes are the most economically and biotechnologically valuable prokaryotes. They are responsible for the production of half of the discovered bioactive secondary metabolites ${ }^{3}$. Marine soils as a source of bioactive actinomycetes were less exploited. In the present study, one natural saline habitat along the Chirala coast of Andhra Pradesh was selected for the isolation followed by assessment of lipolytic potential of marine actinomycetes.

\section{MATERIALS AND METHODS:}

Sampling procedure: Three marine soil samples were collected from the Bay of Bengal near Chirala sea coast at a depth of 10 inches and all samples were transferred into sterile zipped polythene bags and transported to the laboratory for the isolation of actinomycetes. The locations and depths of these sampling stations are summarized in Table $\mathbf{1 .}$

Isolation of Actinomycetes colonies from Marine soils: Soil samples collected were subjected to $\mathrm{CaCO}_{3}$ treatment for better isolation of actinomycetes. Isolation and enumeration of actinomycetes were performed by the serial dilution plate technique using starch casein agar medium ${ }^{4}$. All plates were incubated at $28 \pm 2^{\circ} \mathrm{C}$ for 2-3 weeks. After incubation, actinomycetes isolates were distinguished from other microbial colonies which are partially submerged into the agar and colors of pigmentation including diffusible pigments. Single separated actinomycetes colonies were selected and the subcultures were maintained on starch casein slants at $4^{\circ} \mathrm{C}$ until further Use.

\section{Primary screening for lipolytic Actinobacteria:}

For the detection of lipolytic actinobacteria, tributyrin agar clearing method was followed ${ }^{2}$. Twenty $\mathrm{ml}$ of tributyrin agar medium was inoculated with a loopful of isolating and incubated at $28^{\circ} \mathrm{C}$ for five days. The composition of tributyrin agar medium is $(\mathrm{g} / \mathrm{l}):\left(\mathrm{NH}_{4}\right)_{2} \mathrm{SO}_{4}-5, \mathrm{Na}_{2} \mathrm{HPO}_{4}-$ 6, $\mathrm{KH}_{2} \mathrm{PO}_{4}-2, \mathrm{MgSO}_{4}-3, \mathrm{CaCl}_{2}-3$, agar - 20 and tributyrin $-10 \mathrm{ml}$ with $\mathrm{pH}$ 6.0. Lipolytic zone of the isolates was measured and these isolates were subjected to secondary screening by submerged fermentation.

Secondary screening for lipase production: For the production of lipase, the isolates were cultivated in a synthetic medium containing olive oil as the sole carbon source under submerged fermentation conditions and assayed for the lipolytic activity of the culture filtrates. $50 \mathrm{ml}$ of production medium is taken in a $250 \mathrm{ml}$ Erlenmeyer flask and inoculated with a loopful culture of each isolate. The flasks were incubated at $28^{\circ} \mathrm{C}$ for 10 days on a rotary shaker (120 rpm). The culture broth was filtered and the clear filtrate was used as the source of the crude enzyme. The composition of the production medium is $(\mathrm{g} / \mathrm{l})$ : Olive Oil -10 , $\left(\mathrm{NH}_{4}\right)_{2} \mathrm{SO}_{4}-5, \mathrm{Na}_{2} \mathrm{HPO}_{4}-6, \mathrm{KH}_{2} \mathrm{PO}_{4}-2$, $\mathrm{MgSO}_{4}-3, \mathrm{CaCl}_{2}-3$ with $\mathrm{pH} 6.0^{2}$.

Lipase assay: The culture broth was filtered and the lipase activity in the culture filtrate was determined by titrimetric method using olive oil as substrate $^{5}$. One unit of enzyme activity is defined as the amount of enzyme required to liberate $1 \mu$ mole equivalent fatty acid $/ \mathrm{ml} / \mathrm{min}$ at $37{ }^{\circ} \mathrm{C}$ under the standard assay conditions. All the experiments were carried out in triplicate and the mean of the three values was presented.

Enzyme profile of the selected strain: Qualitative screening for different enzyme production by the selected strain was done by plate assay method. Agar plates were prepared by incorporating the corresponding substrate in starch agar medium. The clear zones were visualized by the methods specific for each of the enzyme. The substrates used for plate assay were carboxy methyl cellulose (cellulase), pectin (pectinase), Casein (protease) starch (amylase) and PHB (PHB depolymerase). Production of amylase was visualized by flooding the plates with iodine solution ${ }^{6}$, while pectinase production was visualized using cetrimide ${ }^{7}$. Congo red was used in the case of cellulose ${ }^{8}$. Protease and PHB depolymerase production was detected by observing the clear zones formed around the colony 9,10 .

Preliminary identification of the Actinomycetes isolates: The actinomycetes isolate were identified up to the genus level by macroscopic and microscopic morphological methods ${ }^{11}$. The macroscopic method was done by colony characterization on yeast malt extract agar (YMA) medium. Colour of colony and presence of pigmentation were noted. The microscopic characterization was done by slide culture method observed after three days. 
The presence or absence of aerial and substrate mycelium. Spore formation and pigmentation of the vegetative or substrate mycelium were observed. Further characterization of selected isolate was done as per the ISP protocol. The utilization of carbon sources was examined on Pridham and Gottleib's medium containing miscellaneous carbohydrates to a final concentration of $1 \%$. Physiological characterization of actinomycetes carried out by performing the growth at different temperatures range from 15 to $45^{\circ} \mathrm{C}, \mathrm{pH}$ range from 4.5 to 9.5 and sodium chloride tolerance $(2,4,6,8$ and $10 \% \mathrm{w} / \mathrm{v})$. Biochemical characterization was done by performing indole test, methyl red test, voges proskauer test, citrate utilization, casein hydrolysis, urea hydrolysis, nitrate reduction, $\mathrm{H}_{2} \mathrm{~S}$ production and catalase test.

DNA isolation, amplification and sequencing of the 16S rRNA gene: The selected actinomycete strain was grown for 6 days on a starch agar slant at $30^{\circ} \mathrm{C}$. Two $\mathrm{ml}$ of a spore suspension were inoculated into the starch nitrate broth and incubated for 4 days on a shaker incubator at 200 $\mathrm{rpm}$ and $30^{\circ} \mathrm{C}$ to form a pellet of vegetative cells (pre-sporulation). The preparation of total genomic DNA was conducted as described by ${ }^{12}$. PCR amplification of the 16S rRNA gene of the selected actinomycete strain was conducted as described by ${ }^{13}$. The PCR reaction mixture was analyzed via agarose gel electrophoresis and purified using QIA quick PCR purification reagents (Qiagen, USA). The 16S rRNA gene was sequence on both strands via the dideoxy chain termination method ${ }^{14}$. The similarity of the isolated strain (16S rDNA sequence) with the existing strains was tested by comparing the $16 \mathrm{~S}$ rDNA sequences available in the NCBI databank using BLAST search. The DNA sequences were aligned and a phylogenetic tree was constructed by the neighbor joining method using Clustal W software ${ }^{15}$ and 100 replicates were carried out for bootstrap analysis ${ }^{16}$.

\section{Secondary structure prediction and Restriction} site analysis: The RNA secondary structure of the selected isolate was predicted using Gene Bee online software (http://www.genebee.msu.su/ services/rna2_reduced.html) by greedy method and the restriction sites in the DNA of the strain were analyzed by NEB Cutter Version 2.0 (http://tools.neb.com/NEBcutter2/).

\section{RESULTS AND DISCUSSION:}

Isolation of Actinomycetes colonies from Marine soils: Six actinomycetes strains were isolated from the Bay of Bengal near Chirala coast of Andhra Pradesh using starch casein agar medium (Table 1). Two samples of Chirala are found suitable for the isolation of actinomycetes. High or low number of active strains found depends on many factors like the medium and methods of screening. Moreover, there are so many factors which affect actinomycetes growth and enzyme production, including the chemical and biological environment.

TABLE 1: DISTRIBUTION OF ACTINOMYCETES IN VARIOUS SAMPLES

\begin{tabular}{ccccc}
\hline S.no & Collecting area & Abbreviated Name & Characters & Total no of actinomycetes \\
\hline 1 & Vadarevu & VRBS & Dry, stony brown soil & 2 \\
2 & Ramapuram & RPBS & Dry, stony reddish soil & 4 \\
3 & Vetapalem & VPBS & Dry, stony blackish soil & - \\
\hline
\end{tabular}

\section{Primary screening for lipolytic Actinobacteria:}

All the isolates showed lipolytic activity. This suggests that marine soils of Chirala are good sources for isolating lipolytic actinomycetes. Only few reports of lipases from marine actinomycetes were made by previous researchers although marine actinomycetes have an excellent capacity to elaborate a wide diversity of enzymes ${ }^{17}$. As indicated in the figure, isolate RPBS-A4 showed maximum lipolytic activity after primary screening (Fig.1). Screening with the help of tributyrin is a convenient and presumptive test for the detection of lipolytic organisms; hence all the isolates were screened using tributyrin agar clearing method.

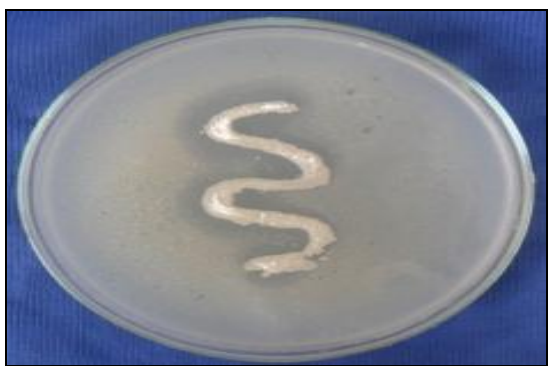

FIG. 1: LIPASE ENZYME ACTIVITIES OF THE POTENTIAL ISOLATE RPBS-A4 
Secondary screening for lipase production: All the isolates were subjected to submerged fermentation conditions and assayed for lipolytic activity quantitatively. Since tributyrin is not a substrate for lipases alone, all the isolates are confirmed for their lipolytic activity by the hydrolysis of natural triglyceride (triolein) under submerged fermentation conditions and the results are presented in (Fig.2). As showed in the Fig.2, the isolate RPBS-A4 showed maximum lipolytic activity of $12.5 \mathrm{U}$ among all the isolates. Optimization of nutritional and physical parameters for the reduction of cost in industrial scale production and presence of other bioactive compounds influencing lipolytic activity of the isolate had to be determined to determine the potency of RPBS-A4. But our study focuses on screening of marine soils for lipolytic actinobacteria which have been accomplished.

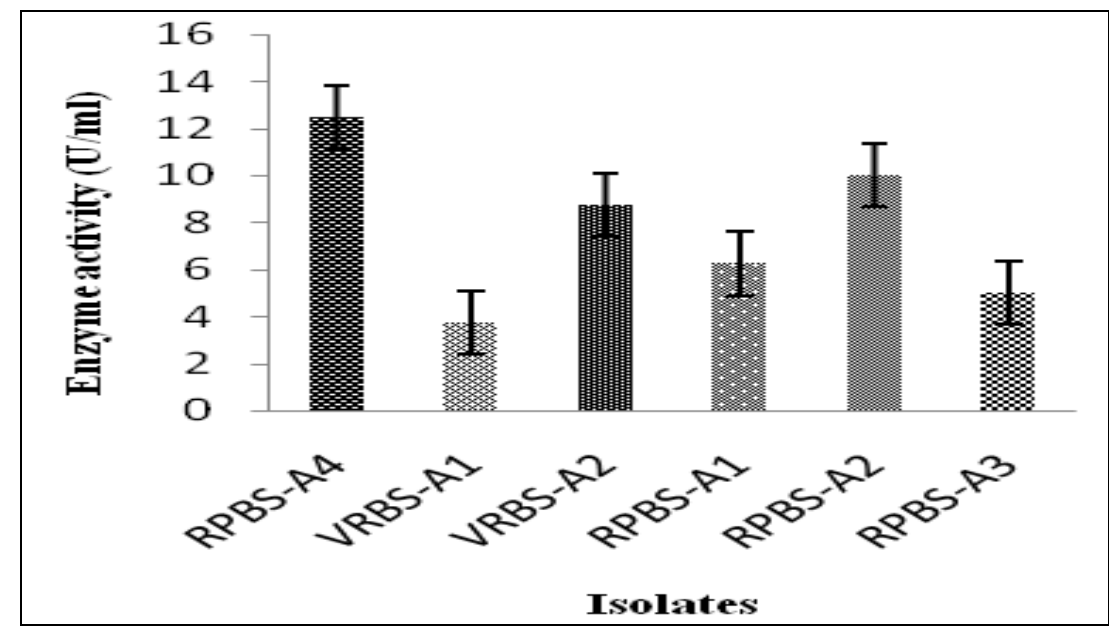

FIG. 2: LIPOLYTIC ACTIVITY OF THE ISOLATES UNDER SUBMERGED FERMENTATION CONDITIONS

Enzyme profile of the selected strain: In addition to the production of lipase, the strain RPBS-A4 was found to be producing other commercially important enzymes such as cellulase, amylase, pectinase Protease and PHB depolymerase (Fig.3).
The clear zone is formed around the spot inoculated culture was taken as the measure for detecting the enzyme production. From the Fig.3, it is clear that the strain is a potent producer of cellulase, amylase, protease, pectinase and PHB depolymerase.

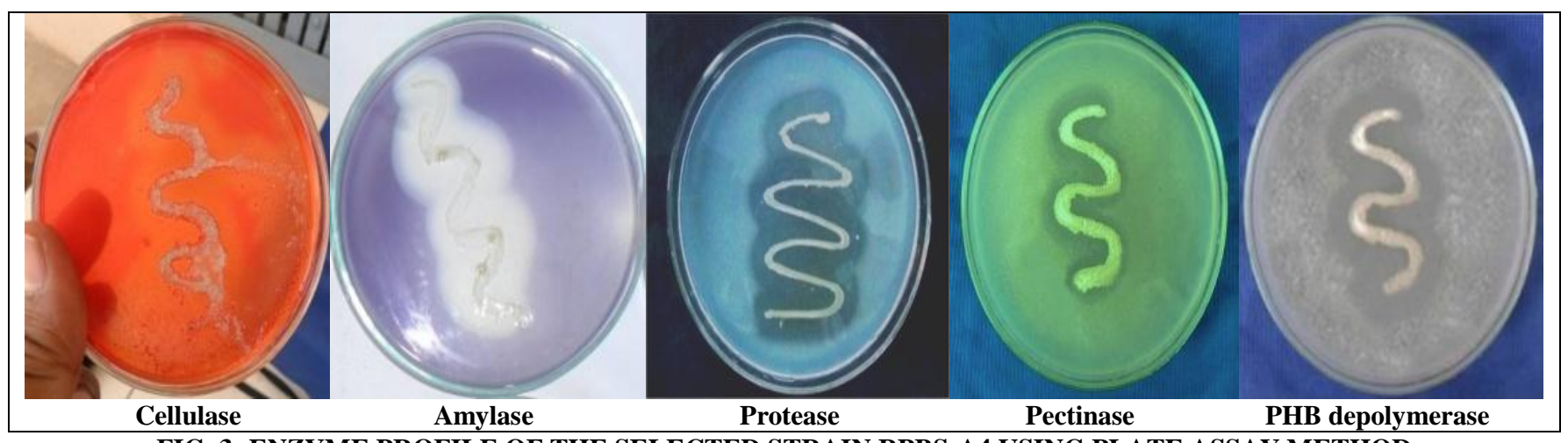

FIG. 3: ENZYME PROFILE OF THE SELECTED STRAIN RPBS-A4 USING PLATE ASSAY METHOD

Preliminary identification of the Actinomycetes isolates: All the isolates were subjected to characterization up to genus level. The culture and morphological properties of the six isolates is shown in Table 2. The results indicate that aerial and substrate mycelium colour of all strains were white to grey on media tested (Fig.4). The aerial mycelium and spore mass were light grey (RPBS-
A1, RPBS-A4), Whitish grey (RPBS-A2), dark grey (RPBS-A3, VRBS-A2) and whitish brown (VRBS-A1) in colour. The colonies appeared leathery till the development of substrate mycelia but gained powdery, cottony and velvety or ash like appearance as aerial spore mass developed. 
According to Waksman ${ }^{18}$ such colour and form is exhibited by colonies of both Streptomyces and Micromonospora. However, the colour of the growth and the form of the colony could not serve as basis of pointing out the genus to which actinomycetes isolates belongs to. Hence, its morphological properties must serve as the primary basis of characterization. All the isolates formed substrate mycelium and abundant aerial mycelium with powdery spore mass. Polysporic actinomycetes, forming characteristic aerial and substrate hyphae represent an important microscopic criterion to identify the genus Streptomyces ${ }^{19}$.

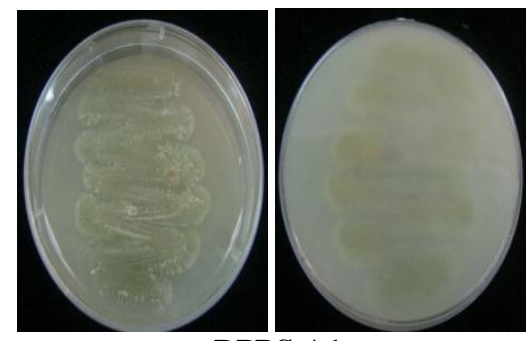

RPBS-A1

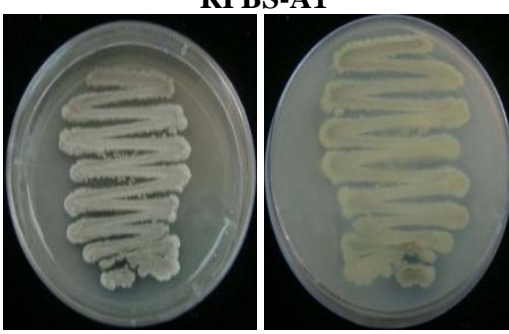

RPBS-A4

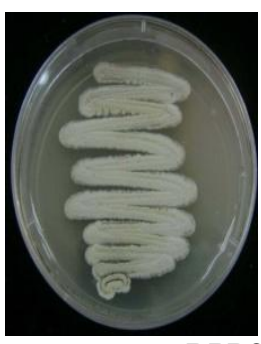

RPBS-A2

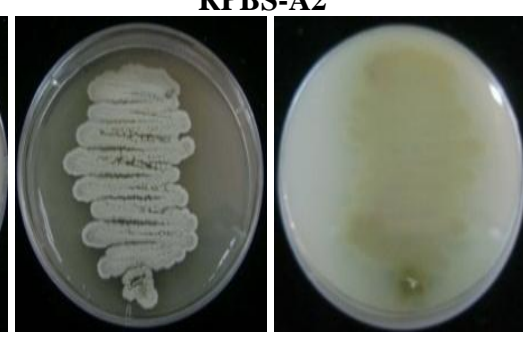

VRBS-A1

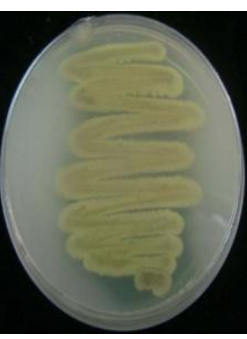

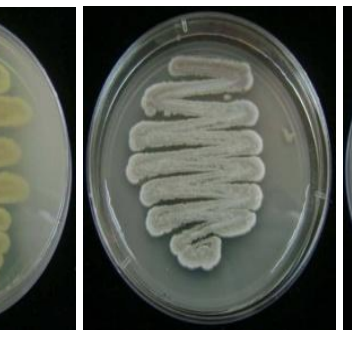

RPBS-A3

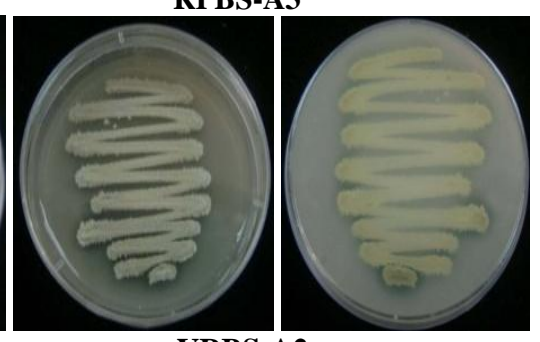

VRBS-A2

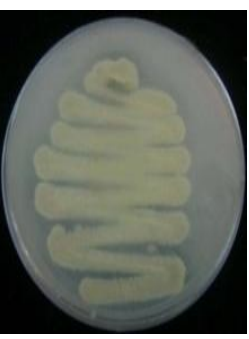

FIG.4: AERIAL AND SUBSTRATE MYCELIUM OF 7DAY OLD CULTURE OF ISOLATED STRAINS ON SCA MEDIUM. LEFT: AERIAL MYCELIUM, RIGHT: SUBSTRATE MYCELIUM

Micro morphology of the isolates was examined using the slide culture technique. All the isolates showed fragmented aerial mycelium with spiral spore chains (Fig.5). As the sporogenous hyphae were spiral in nature, the isolates may be placed in the spiral group.

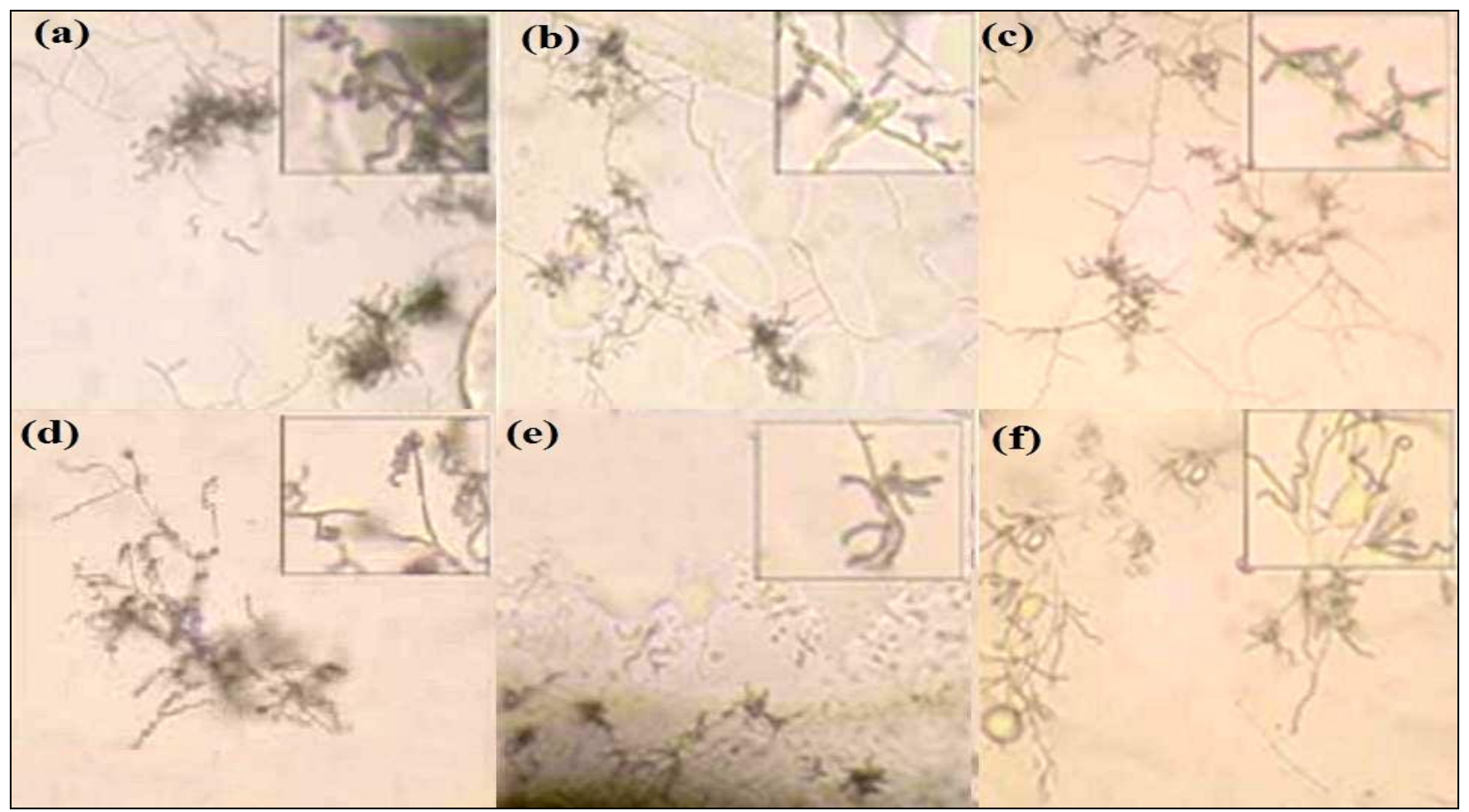

FIG. 5: LIGHT MICROGRAPHS OF ISOLATED STRAINS; (a) RPBS-A1, (b) RPBS-A2, (c) RPBS-A3, (d) RPBS-A4, (e) VRBS-A1 AND (f) VRBS-A2 SHOWING STRUCTURE OF SPORE CHAINS AND SURFACE SPORES ON YEAST EXTRACT MALT EXTRACT AGAR 
The physiological and biochemical characteristics of the isolates are shown in Table 2. Kamfer et al. (1991) ${ }^{20}$ suggested that physiological tests are indispensable tools for classification and identification of actinomycetes. All the isolates exhibited positive reaction to melanin pigmentation. Isolates RPBS-A1 and RPBS-A2 had the ability for $\mathrm{H}_{2} \mathrm{~S}$ production and nitrate reductase was secreted by all the isolates except VRBS-A2. All the isolates were positive for casein hydrolysis and gelatin hydrolysis. Carbohydrate utilization test plays a prominent role in the taxonomic characterization of actinomycetes strains ${ }^{21}$. Abundant growth was attained with glucose, maltose, mannose and trehalose by all the isolates used. However, little or no growth was attained when isolates RPBS-A1, RPBS-A2 and RPBS-A3 were grown on sorbitol, adonitol, raffinose and glycerol. Isolate RPBS-A4 efficiently utilized all the carbon sources tested. Whereas sorbitol, mannose, trehalose, glucose and fructose were assimilated by the isolate VRBS-A1 as the good source of carbon and energy while maltose, mannose, xylose, trehalose, glucose, fructose and galactose were well utilized by the isolate VRBSA2.

Tolerance of the strain of $\mathrm{NaCl}$ concentration also serves as an important character for species identification. Three strains $(50 \%)$ out of six tested strains grew at $2 \%$ up to $10 \% \mathrm{NaCl}$. These strains were RPBS-A1, RPBS-A2 and RPBS-A4. The remaining strains grew up to $6 \% \mathrm{NaCl}$ for strain VRBS-A2 and up to $8 \% \mathrm{NaCl}$ for strain RPBS-A3 and VRBS-A1. All the isolates exhibited salt tolerance up to $6 \%$, indicating that the isolates are indigenous to the marine environment.

All the isolates grown well at $15-35^{\circ} \mathrm{C}$. At $15^{\circ} \mathrm{C}$. Only strains RPBS-A1 and VRBS-A1 had poor growth whereas the other strains were fully grown on the media. One third of the strains (RPBS-A3 and VRBS-A1) could not grow at temperature $45^{\circ} \mathrm{C}$; whereas the remaining strains, which were RPBS-A2 and VRBS-A2, had poor growth at $45^{\circ} \mathrm{C}$. However, strains RPBS-A1 and RPBS-A4 seemed to be well grown at $45^{\circ} \mathrm{C}$. All the isolates had good growth between $\mathrm{pH} 6.5$ to 9.5 , and not growing at all on $\mathrm{pH}$ 4.5. However, the result exhibited half of the test strains (RPBS-A1, RPBS-A2 and VRBSA1) grew poorly with a pH level of 5.5, whereas the remaining strains had quite good growth with sporulation on the media with the same $\mathrm{pH}$ level. On the basis of morphological, physiological and biochemical characteristics, all the isolates were identified as belonging to the family of Steptomycetaceae and the genus Streptomyces ${ }^{22}$. This suggests that the natural substrates such as marine soils are also good sources for isolation of lipolytic actinobacteria.

TABLE 2: MORPHOLOGICAL, PHYSIOLOGICAL AND BIOCHEMICAL CHARACTERIZATION OF THE ISOLATES

\begin{tabular}{|c|c|c|c|c|c|c|}
\hline Test & RPBS-A1 & RPBS-A2 & RPBS-A3 & RPBS-A4 & VRBS-A1 & VRBS-A2 \\
\hline \multicolumn{7}{|c|}{ Morphological features of actinomycetes } \\
\hline Aerial mycelium & Light grey & Grayish White & Dark grey & Light grey & White & Dark grey \\
\hline Substrate mycelium & White & Dark brown & White & White & Dark brown & Light Brown \\
\hline \multicolumn{7}{|c|}{ Physiological characterization of isolates } \\
\hline $\mathrm{p}^{\mathrm{H}} 4.5$ & - & - & - & - & - & - \\
\hline $\mathrm{p}^{\mathrm{H}} 5.5$ & + & + & +++ & +++ & + & +++ \\
\hline $\mathrm{p}^{\mathrm{H}} 6.5$ & +++ & +++ & +++ & +++ & +++ & +++ \\
\hline $\mathrm{p}^{\mathrm{H}} 7.5$ & +++ & +++ & +++ & +++ & +++ & +++ \\
\hline $\mathrm{p}^{\mathrm{H}} 8.5$ & +++ & +++ & +++ & +++ & +++ & +++ \\
\hline $\mathrm{p}^{\mathrm{H}} 9.5$ & +++ & +++ & +++ & +++ & +++ & +++ \\
\hline \multicolumn{7}{|c|}{ Temperature $\left( \pm 2^{\circ} \mathrm{C}\right)$} \\
\hline $15^{\circ} \mathrm{C}$ & + & +++ & +++ & +++ & + & +++ \\
\hline $25^{\circ} \mathrm{C}$ & +++ & +++ & +++ & +++ & +++ & +++ \\
\hline $35^{\circ} \mathrm{C}$ & +++ & +++ & +++ & +++ & +++ & +++ \\
\hline $45^{\circ} \mathrm{C}$ & +++ & + & - & +++ & - & + \\
\hline \multicolumn{7}{|c|}{ Salt tolerance of the isolates } \\
\hline $2 \%$ & +++ & +++ & +++ & +++ & +++ & +++ \\
\hline $4 \%$ & +++ & +++ & +++ & +++ & +++ & +++ \\
\hline $6 \%$ & +++ & +++ & +++ & +++ & +++ & +++ \\
\hline $8 \%$ & +++ & +++ & +++ & +++ & +++ & - \\
\hline $10 \%$ & +++ & +++ & - & +++ & - & - \\
\hline \multicolumn{7}{|c|}{ Biochemical characterization of the isolates } \\
\hline Indole & - & - & - & - & - & - \\
\hline Methyl Red & - & + & - & + & - & + \\
\hline
\end{tabular}




\begin{tabular}{|c|c|c|c|c|c|c|}
\hline Voges Proskauer & - & - & - & - & - & - \\
\hline Citrate & - & + & - & - & + & - \\
\hline $\mathrm{H}_{2} \mathrm{~S}$ & + & + & - & - & - & - \\
\hline Nitrate reduction & + & + & + & + & + & - \\
\hline Melanin Production & + & + & + & + & + & + \\
\hline \multicolumn{7}{|c|}{ Carbon utilization } \\
\hline Maltose & + & + & + & + & \pm & + \\
\hline Sorbitol & - & - & - & + & + & - \\
\hline Rhamnose & \pm & + & + & + & \pm & \pm \\
\hline Raffinose & - & - & - & + & - & - \\
\hline Mannose & + & + & + & + & + & + \\
\hline Sucrose & - & + & \pm & + & \pm & - \\
\hline Xylose & + & + & \pm & + & \pm & + \\
\hline Trehalose & + & + & + & + & + & + \\
\hline Adonitol & - & - & - & \pm & - & - \\
\hline glucose & + & + & + & + & + & + \\
\hline Fructose & - & + & + & + & + & + \\
\hline Lactose & - & - & + & + & - & - \\
\hline Inositol & - & - & \pm & + & \pm & \pm \\
\hline Galactose & - & - & + & + & + & + \\
\hline \multicolumn{7}{|c|}{ Production of enzymes by the isolates } \\
\hline Catalase & + & + & + & + & + & + \\
\hline Urease & - & - & - & - & - & - \\
\hline Casein hydrolysis & + & + & + & + & + & + \\
\hline
\end{tabular}

+; good growth, \pm ; poor growth, -; no growth

\section{Molecular phylogeny of the selected isolate:}

Genomic DNA from the selected isolate RPBS-A4 extracted was found to be of good quality as visualized by agarose gel electrophoresis. The extracted DNA was intact. Clean and free of RNA. The molecular characterization, of isolate RPBSA4 was carried out after PCR amplification of the $16 \mathrm{~S}$ rDNA sequence of the genomic DNA using the universal forward and reverse primers. The bidirectional sequencing of $16 \mathrm{~S}$ rDNA of the isolate revealed the presence of $518 \mathrm{bp}$ and of the BLAST search of the sequence showed maximum (97\%) identity with Streptomyces fungicidicus
(FMA204) and Phylogenetic tree was constructed with bootstrap values (Fig.6). Based on molecular taxonomy and phylogeny, the strain was identified as novel Streptomyces species and designated as Streptomyces fungicidicus RPBS-A4. The 16S rDNA sequence of Streptomyces fungicidicus RPBS-A4 has been deposited in the GenBank (NCBI, USA) under the accession number KF751609. A neighbor-joining tree based on 16S rDNA sequences showed that the isolate occupies a distinct phylogenetic position within the radiation including representatives of the family Streptomycetes.

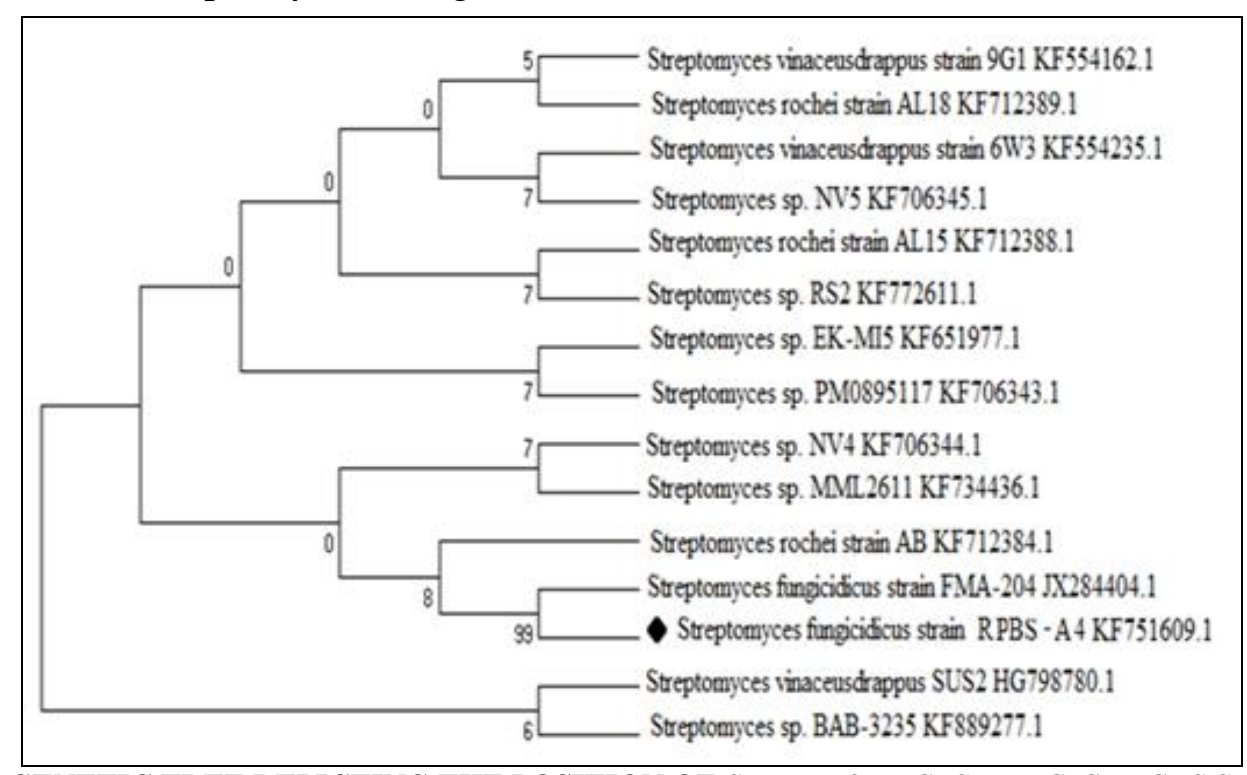

FIG. 6: PHYLOGENETIC TREE DEPICTING THE POSITION OF STREPTOMYCES FUNGICIDICUS STRAIN. RPBS-A4 
Secondary structure prediction and Restriction site analysis: The sequence obtained for RPBS-A4 was used to deduce the secondary structure of RNA using Gene Bee (Fig.7). It showed that the free energy of the structure is $-124.0 \mathrm{kcal} / \mathrm{mol}$. Threshold energy is -4.0 with cluster factor 2, conserved factor 2 and compensated factor 4 and conservativity is 0.8 . There have been attempts to predict the secondary structure of rRNA gene sequence using Gene Bee ${ }^{23}$. The prediction of restriction sites of the strain RPBS-A4 showed the restriction sites for various enzymes such as BstN I, Acc651I, Eco NI and BsaHI etc (Fig. 8). It shows GC and AT content of 61 and 39\%, respectively.

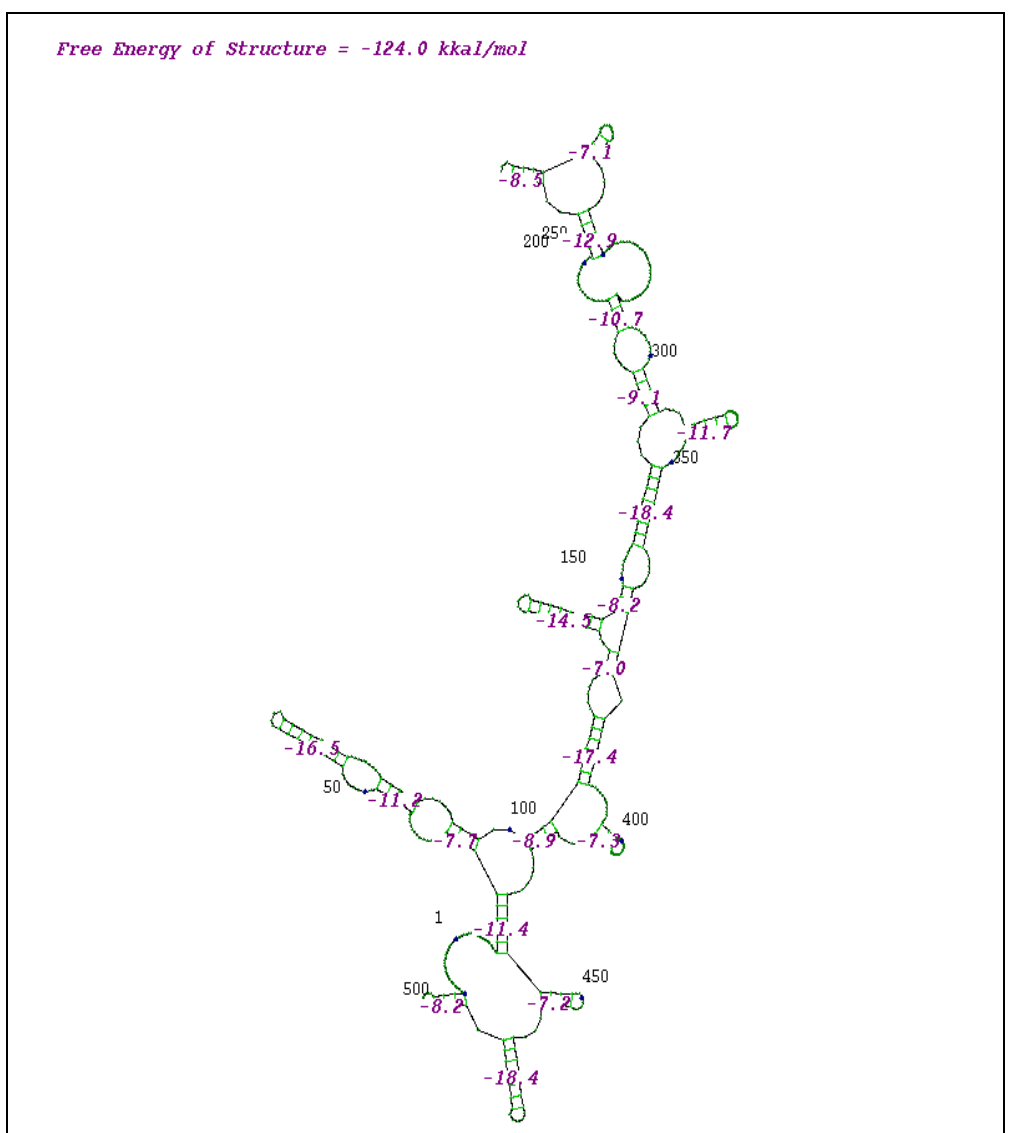

FIG.7: SECONDARY STRUCTURE PREDICTION OF 16S rRNA OF THE STRAIN STREPTOMYCES FUNGICIDICUS RPBS-A4 WAS DONE USING GENEBEE ONLINE SOFTWARE

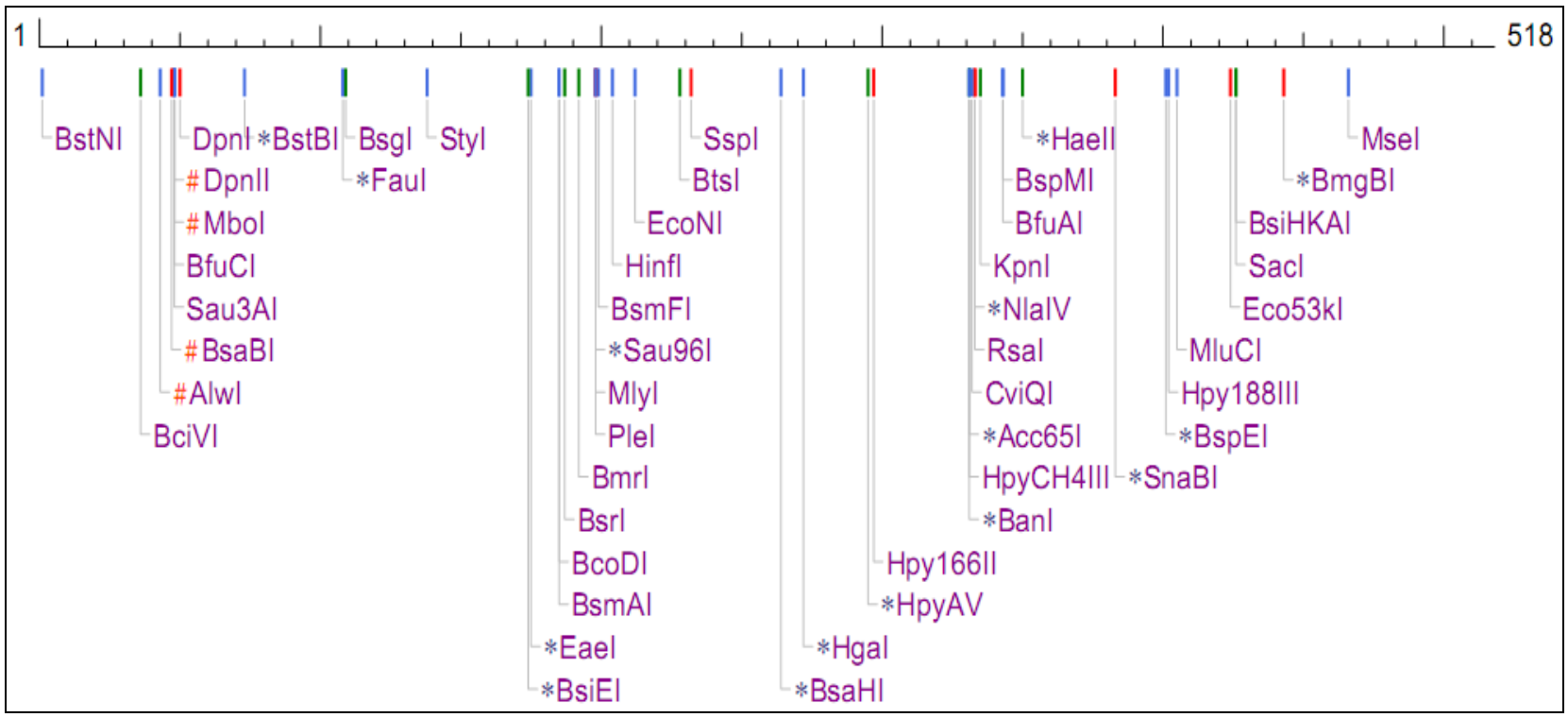

FIG. 8: RESTRICTION SITES OF THE STRAIN STREPTOMYCES FUNGICIDICUS RPBS-A4 WAS PREDICTED USING NEB CUTTER 
CONCLUSION: Based on the screening results it had been shown that marine soils of Chirala coast, Bay of Bengal possess lipolytic actinomycetes and maybe tapped as one of the potential source for lipase production. The results in general reflect on the lipase production potentiality among the relatively less explored group of marine actinomycetes. It is suggested that frequent and systematic screening for actinomycetes in the Bay of Bengal could provide novel species as well as promising lipolytic Actinobacteria.

ACKNOWLEDGMENT: The authors would like to thank Dept of Biotechnology and Environmental sciences of Sri Venkateswara University, Tirupati, for providing the required infrastructural facilities.

CONFLICT OF INTEREST: The authors declare that they have no conflict of interest.

\section{REFERENCES:}

1. Selvam K and Vishnupriya B: Partial purification of lipase from Streptomyces variabilis NGP 3 and its application in bioremediation of waste water. International Journal of Pharmaceutical Sciences and Research 2013; 4(11): 42814289.

2. Bindiya $\mathrm{P}$ and Ramana $\mathrm{T}$ : Optimization of lipase production from an indigenously isolated marine Aspergillus sydowii of Bay of Bengal. Journal of Biochemical Technology 2012; 3(5): S203-S211.

3. Mukesh Sharma: Actinomycetes: Source, Identification, and Their Applications. International Journal of Current Microbiology and Applied Sciences 2014; 3(2): 801-832.

4. Aparanji P, Venkata Ramana L and Murali Krishna R: Isolation of potent antibiotic producing Actinomycetes from marine sediments of Andaman and Nicobar Marine Islands. Journal of Microbiology and Antimicrobials 2013; 5(1): 6-12.

5. Bhavani M, Chowdary GV, David M, Archana G: Screening, Isolation and Biochemical Characterization of Novel Lipase Producing Bacteria from Soil Samples. International Journal of Biological Engineering 2012; 2(2): 18-22.

6. Kar S and Ray RC: Partial characterization and optimization of extracellular thermostable $\mathrm{Ca} 2+$ inhibited $\alpha$-amylase production by Streptomyces erumpens MTCC 7317, Journal of Scientific and Industrial Research 2008; 67 (1): 58-64.

7. Saadoun I, Rawashdeh R, Dayeh $\mathrm{T}$, Ababneh Q, and Mahasneh A. Isolation, characterization and screening for fibre hydrolytic enzymes-producing Streptomycetes of Jordanian forest soils. Biotechnology 2007; 6(1): 120 128.
8. Ariffin H, Abdullah N, Kalsom M.S.U, Shirai Y and Hassan M.A. Production and characterization of cellulase by Bacillus pumilus EB 3.International Journal of Engineering and Technology 2006; 3: 47-53.

9. Mathew J, Latha M.S and Ravindran PC. Production of alkaline protease from Bacillus pumillus K242 by solid state fermentation. Asian Journal of Microbiology Biotechnology and Environmental Science 2005; 7(3): 617-621.

10. WANG Yan, LI Fan, WANG Zhan-yong, LIU Dong-bo, XIA Hong-mei, LIU Ling-fei and CHEN Shan. Purification and Properties of an Extracellular Polyhydroxybutyrate Depolymerase from Pseudomonas mendocina DSWY0601. Chemical Research in Chinese Universities 2012, 28(3): 459 - 464.

11. Deepthi Augustine, Jimly C, Jacob, Ramya KD, and Rosamma Philip: Actinobacteria from sediment samples of Arabian Sea and Bay of Bengal. International Journal of Research in Marine Sciences 2013; 2(2): 56-63.

12. Wilson K: Preparation of genomic DNA from bacteria. In current protocol in molecular biology 1990; (Ausubel, F. A., Brent, R., Kingstan, R. E., Moore, D. D., Smith, J. A., Seidmen, J. G. and Struhi, K., Eds.), Chapter 2-4, Greene Publishing and Wiley inter Science, Newyork.

13. Weisburg WG, Barns SM, Pelletier DA and Lare DJ: 16S rDNA amplification for phylogenetic study. Journal of Bacteriology1991; 173:697-703.

14. Sanger F, Nicklen $S$ and Coulson AR: DNA sequencing with chain terminator inhibitors. Proc. Natural Academy of Science 1977; 74: 5463-5467.

15. Saitou N, Nei M: The neighbor-joining method: a new method for reconstructing phylogenetic trees. Molecular Biology Evolution 1987; 24:189-204.

16. Suthindhiran K and Kannabiran K: Hemolytic activity of Streptomyces VITSDK1 sp. isolated from marine sediments in Southern India. Journal de Mycologie Médicale 2009; 19:77-86.

17. Sharma R, Chisti Y and Banerjee UC: Production, purification, characterization, and applications of lipases. Biotechnology Advances 2001; 19:627-662.

18. Waksman SA: The actinomycetes: classification, identification and descriptions of genera and species. Baltimore 1961; The Williams and Wilkins Company.

19. Bergey: Manual of Determined Bacteriology Actinomycetales 2000; (9th Ed.).

20. Kampfer P, Kroppenstedt RM and Dott W: A numerical classification of the genera Streptomyces and Streptosverticillum using miniaturized physiological tests, Journal of General Microbiology 1991; 137:1831-1891.

21. Pridham TG and Gottleib D: The utilization of carbon compounds by some actinomycetes as an aid for species determination. Journal of Bacteriology 1948; 56:107-114.

22. Pridham TG, Hesseltine $\mathrm{CW}$ and Benedict RG: A guide for the classification of Steptomycetes according to selected groups. Applied Microbiology 1958; 6:52-79.

23. Thenmozhi M and Kannabiran K: Studies on Isolation, Classification and Phylogenetic Characterization of Novel Antifungal Streptomyces sp. VITSTK7 in India. Current Research Journal of Biological Sciences 2010; 2(5): 306312.

How to cite this article:

Rajanikanth A and Damodharam T: Screening of marine soils from Bay of Bengal near chirala coast of Andhra Pradesh for isolation of lipolytic actinobacteria and characterization of the most potent isolates. Int J Pharm Sci Res 2017; 8(1): 182-90.doi: 10.13040/IJPSR.0975-8232.8(1).182-90.

All @ 2013 are reserved by International Journal of Pharmaceutical Sciences and Research. This Journal licensed under a Creative Commons Attribution-NonCommercial-ShareAlike 3.0 Unported License.

This article can be downloaded to ANDROID OS based mobile. Scan QR Code using Code/Bar Scanner from your mobile. (Scanners are available on Google Playstore) 